\title{
Mechanical Engineering Extensibility Training Project Development Based on 3D Technology
}

\author{
Song xin \\ College of Engineering and Technology \\ Tianjin Agricultural University \\ Tianjin, China \\ songxin-tju@163.com \\ Li Yancong \\ College of Engineering and Technology \\ Tianjin Agricultural University \\ Tianjin, China \\ lyc65@163.com
}

\author{
Shi Yu \\ College of Engineering and Technology \\ Tianjin Agricultural University \\ Tianjin, China \\ syych83@tjau.edu.cn \\ Shan Huiyong \\ College of Engineering and Technology \\ Tianjin Agricultural University \\ Tianjin, China \\ tjshy@sohu.com
}

\begin{abstract}
The mechanical engineering extensibility training project based on 3D technology is proposed in the paper. Based on the practical engineering, students are required to complete components design, processing, manufacture, assembly and application by using threedimensional digital design and 3D printing technology. Virtual simulation and physical production are combined to solve the problems such as boring, abstract and understanding hard in classroom teaching. Interactivity in teaching and realistic of engineering practice are enhanced. In addition to this, it can make students to further consolidate professional knowledge, improve the ability of engineering practice, stimulate the innovation awareness, and obtain personal comprehensive development of knowledge, ability and quality. The practice training project has been carried out in six classes which belongs to three grades of agricultural machinery and automation and achieved good effect. More than 200 students have obtained the great benefit from the activities of innovation, competition and scientific research.
\end{abstract}

Keywords-three-dimensional model; $3 D$ technology; $3 D$ printer;extensibility training project; group learning mechanism

\section{INTRODUCTION}

At present, with a series of powerful forces including the knowledge economy, globalization, technological innovation, development transformation and demographic characteristics, engineering practice with its education mode is faced with new challenges and opportunities. Faced with complex changes in the social environment, the problem of how to innovate for university education in engineering mode has become a global concern and research focus. Reform and innovation of engineering education mode is not only concerns the technical personnel training quality, but also the position of universities in national economy and social development, furthermore relate to the talent

The research was sponsored by the undergraduate education and teaching research and reform project of Tianjin Agriculture University (2014-B-09) and the teaching reform project of experimental teaching demonstration center in Tianjin Agriculture University (2015SY023, 2015SY018) guarantee for science and continuous development of economic society. Therefore, the direction of engineering education mode reform should make the engineering education built on the subject basis return to its original meaning, and make it more emphasis on practical engineering application and the systemic and integrity of engineering project itself, which is the socalled Big Engineering Education ${ }^{[1]}$. So, it is particularly important for polytechnic universities to make a change from putting too much emphasis on engineering science to more emphasis on engineering system and its background.

In the late 1990s, through a lot of investigation and reflection for national university engineering education, Japanese education institutions think that the mechanical engineering education overemphasize on study of knowledge, while ignores the technology training, as well as comprehensive quality training to technology owners. So Japan established the Japanese Engineers certification organization named JABBEE(Japan Accreditation Board for Engineering Education) for identifying that the mechanical teaching content of national higher education institutions whether has reached the quality and level of regulations, as well as whether the educated has learned the necessary knowledge and owned the most basic skills. Besides, in the personnel training mode of mechanical engineering vocational education in Germany, Austria and UK, the disadvantage of theoretical teaching is that the content is not intuitive, but making up for that with practical teaching. On the contrary, the connotation and theoretical basis of practical teaching would be enhanced by theoretical teaching so that the students could truly obtain a combination of theory and practice. Thus teaching effectiveness has been greatly improved ${ }^{[2]}$.

Recently, our country has also carried out the practical teaching reform and innovation successively in the higher education of mechanical engineering ${ }^{[3-10]}$. But compares with overseas training mode, domestic practical teaching is still very weak, especially there are 
still many problems in the aspect of combining the theoretical teaching, practical teaching and innovative awareness for students. It is necessary to establish a series of teaching systems which are effective, robust, and both focusing on the theory and practice.

Therefore, mechanical engineering extensibility training project based on 3D technology was proposed and has been carried out in agricultural mechanization and automation major in our college.

\section{THE SYSTEM OF TEACHING REFORM AND PRACTICE BASED ON 3D TECHNOLOGY}

Aimed at professional position ability training, the project of mechanical engineering extensibility training based on 3D technology can realize "zero distance between practical teaching and professional positions, and give students comprehensive quality training so that skills learned is consistent with the requirements of future professional jobs for technical staff.

(1) Construct "one main line, two forms, and three stages" as the core of the training project which could highlight professional features. Among them, "one main line" means that mechanism or components of mechanical device design as the main content of practical training content; "Two forms" means that eventually submitted works include two forms: threedimensional digital model and 3D print production; and "three stages" means that the implementation process of whole project including design, production and application stage.

(2) Enrich and consummate the practical training content in order to highlight the operability, authenticity, practicality and flexibility of the professional training. Furthermore, extensibility feature of the practicality training mainly reflects as the FDM (Fused Deposition Modeling) 3D printer is assembled, tested and used to print the self-designed mechanical parts.

(3) According to the academic background and professional capacity of mechanical engineering sophomores and above, choose the practice training contents with higher feasibility to implement verify and evaluate. The program content and implementation methods can be adjusted and improved further based on the evaluation results.

\section{CONSTRUCTION OF TEACHING REFORM CONTENT SYSTEM}

\section{A. The general idea of practices training project}

The general idea of mechanical engineering extensibility training project is shown by Fig.1.The whole practice training process has three stages: design, manufacture and application. In each stage, students can independently carry out the training contents such as mechanism or components of mechanical device design, three-dimensional digital modeling and virtual simulation, physical model and application etc. by using professional knowledge and mechanical design manual, 3D modeling software and 3D printer. Finally, threedimensional digital model and physical models by 3D printer would be submitted as practice training achievement.

Practice training content is divided into two parts: basic training and extensibility training. Basic training includes three parts: 3D printer assembly and test, 3D modeling for the common mechanical parts and physical model printing. The desktop FDM 3D printer DIY kits are selected in training. Before using, students must assemble and test by themselves according to the design drawings and schematics of $3 \mathrm{D}$ printer. 3D printing technology integrates the multi-disciplinary knowledge, such as design, electronics, software and control. In the process of assembly and test, students can make a comprehensive application of multi-disciplinary knowledge, understanding deeply of theoretical knowledge, and improve the practical ability and interesting in learning. On the basis, three-dimensional digital modeling software is used for digital model establishment of standard mechanical parts and the common mechanism, and then the 3D models are imported into the 3D printer software to print physical models and assembly. On the one hand, the obtained physical models can be used for the physical demonstrating in classroom teaching. On the other hand, the students can construct the common mechanical structure using the part models, which could make the direct-viewing impression, strengthen the cognition and comprehension of the mechanical characteristic.

Extensibility training would be developed after completing the basic training, including that using the three-dimensional digital modeling software for mechanisms and mechanical devices to innovative design, virtual assembly and virtual simulation, as well as convert the design scheme into physical model by using 3D printer. The training content can exercise and cultivate the innovation ability of students, and further consolidate, deepen and develop the learned professional knowledge. Additionally, outstanding students and their works can be selected and recommended to participate in the national and provincial professional skills competitions. 


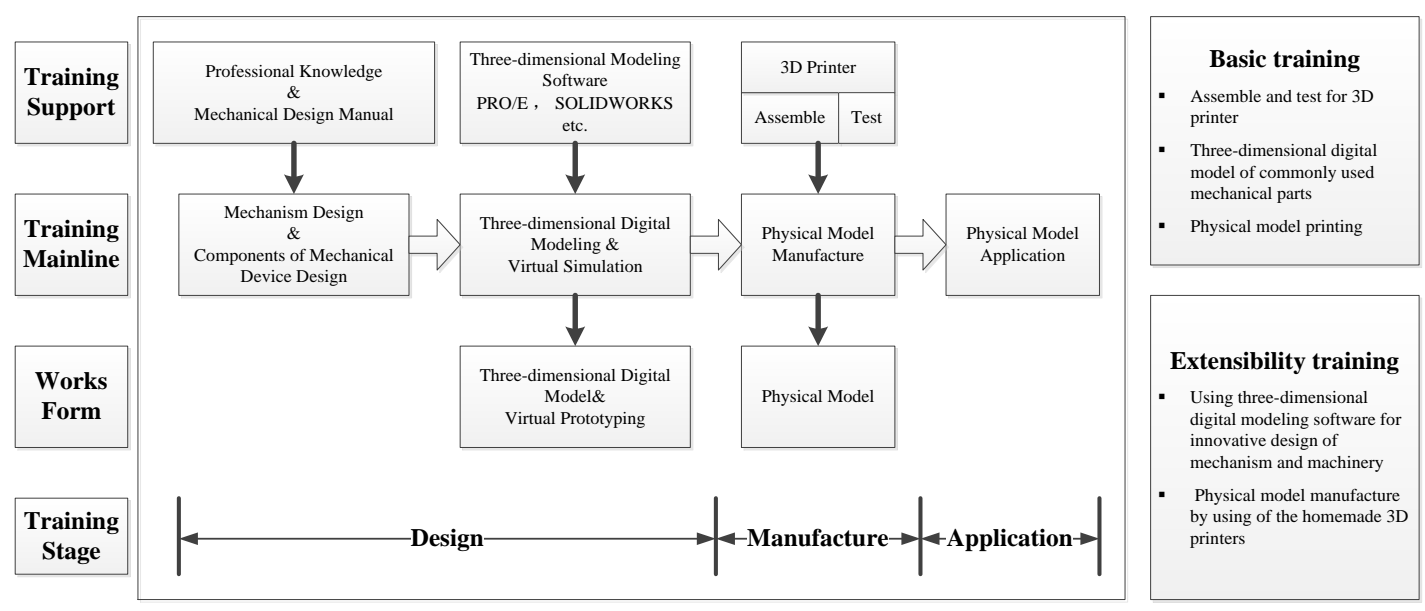

Fig.1. The general idea of practices training project

\section{B. Practice training content design}

(1) 3D design practice training content design

The parts which are compact, relatively amount small, easy to process, and which have agricultural machinery characteristics and practical value are taken as the basis of subject-choice. Then the PRO/E is taken as the main design software. And the entire designing process can be completed, which includes components design, machine virtual assembly and virtual simulation.

(2) 3D printing technology practice training content design

3D printing technology in the teaching content is divided into two parts: one is $3 \mathrm{D}$ printer assembly and test, the other is the application of $3 \mathrm{D}$ printer. The practice training content is organized into four processes: cognition, grasp, design and machining, and application. Firstly, students should have a basic awareness for 3D printing technology through photos, videos and the real object of $3 \mathrm{D}$ printer. The intuitive and visual expression method can greatly stimulate students' interest in 3D printing technology and the enthusiasm for learning. Secondly, by teacher's instruction for specific technologies, principles, ideas and methods, students would learn more technical details of 3D printing technology, and are familiar with the whole assembly and test process. After that the students can assemble and test the 3D printer by themselves. At last, students enter into the essential design stage, according to the design assignment. Then they collected relevant information, sort out the design elements, specifically in the design, modeling and assembly. After that, they made the simulation in three-dimensional digital modeling software and print the design works using 3D printer.

\section{Group learning mechanism}

The 3D technology is a kind of multi-disciplinary integrated technology. Then the using group learning mechanisms can reduce the difficulty of student learning and improve their teamwork. Group learning mechanisms means that every five people is set as a group to obtain a specific topic or study design direction. There is a clear division of responsibilities among team members, and everyone is arranged with their respective tasks. The tasks mainly contain design and processing, which need two students to take charge of the overall design, and the other two students take charge of the processing and assembly of parts, then the last one takes charge of the machine test and practice application.

Group learning mechanisms can make the learning process closer to the actual situation of enterprises. Although the task of everyone is different, they are interlinked with each other, which would make the students study more deeply, have more closely cooperation among the students. And the final submissions are richer and more diversified.

\section{IMPLEMENTATION EFFECT OF THE PRACTICE TRAINING PROJECT}

The practice training project has been carried out in six classes which belongs to three grades of agricultural machinery and automation and achieved good effect. Implementation results show that it can enhance students' practical and innovation ability, by significantly combining project training with task practice in the theory teaching and course design content. Implementation of the project has been last for two years, and the students have participated in all kinds of national and provincial innovative design, academic competitions nearly 10 items. And the number of students received various awards more than 60 . Besides, more than 200 students have obtained the great benefit from the activities of innovation, competition and scientific research.

\section{CONCLUSIONS}

As the training project proposed in the paper, the introduction of 3D technology is an important attempt on practice teaching reform. The primary and intermediate 3D technology is taken as the starting point. Then the multi-disciplinary knowledge design, electronics, software and control are integrated into the existing practice teaching content. It makes the students from puzzled to understand in the learning process of 3D technology, and makes them know the advanced technology more intuitive and truly. So it has important practical significance for the college students to use the 3D technology widely and improve the practical ability. 
Through the implementation of the mechanical engineering extensibility training project based on the 3D technology, the combination of theory and practice in the teaching process has been realized, and the requirements of occupation positions for professionals have been satisfied. The training content of the proposed project has provided strong support for students to attend 3D model contest, pass the vocational skills certification examinations and improve the employability in the future.

\section{ACKNOWLEDGMENT}

In this paper, the research was sponsored by the undergraduate education and teaching research and reform project of Tianjin Agriculture University (2014B-09) and the teaching reform project of experimental teaching demonstration center in Tianjin Agriculture University (2015SY023, 2015SY018).

\section{REFERENCES}

[1] Wang Cheli. Research and practice in engineering education teaching reform based on the idea of large-scale engineering. Higher Education in Chemical Engineering, 2008, 2,pp.7-10.

[2] Zhang Hailu, Zhang Zengfeng, Guo Ruizhi. Machinery "3+1" training mode reform and practice based on 3D technology. China Electric Power Education, 2013, 34,pp.50-51.
[3] Zhou Qiyin. Practice and exploration of mechanical curriculum and course content reform.Journal of University for Staff and Workers of WISGCO, 2000, vol.12(3),pp.72-73.

[4] Jin Weidong,Tang Guoxing,Guo Huai.On strengthening practical teaching for mechanics practice oriented college majors based on pan-region resources.Journal of Changzhou Institute of Technology,2009, vol 22(3),pp.84-87.

[5] Cong Juan. The Construction and innovation of mechanica undergraduate practical teaching system.Journal of Liao Ning Institute of Science and Technology, 2013, vol.15(2),pp.47-48.

[6] Chen Bo,Zhang Jianzhong. The study and practice of teaching reform for mechanical engineering undergraduate professiona based on CDIO model.China Science and Technology Information,2012,15,pp.167,170.

[7] Xie Shikun, Yi Rongxi, Li Qiangzhen,et al. On the teaching reform of mechanical specialty.Journal of Xin Yu college, 2009,vol.14(6), pp. 98-100

[8] Xia Chunming,Wu Qing,Yan Jianjun.Sub-level, multi-module innovation practices and multi-dimensional engineering ability training of machinery and electronics speciality. China University Teaching,2013,2,pp.80-82.

[9] Peng Heping.Reform and Practice on course teaching for mechanical manufacturing-related majors under " $3+1$ " personnel training pattern. Journal of Jianghan university, 2013, vol.41(5), pp.105-108.

[10] Wang Wei,Wang Dianjun,Shen Aiming et al. Reform and exploration of the mechanical and electronic engineering practice teaching system based on CDIO training model.Journal of Anhui Normal University, 2010, vol.33(2), pp.136-138. 